Research Article

\title{
Multiobjective Hydraulic Design and Performance Analysis of a Vortex Pump Based on Orthogonal Tests
}

\author{
Hui Quan (D), Yongkang Wu, Ying Guo, Kai Song, and Yanan Li \\ College of Energy and Power Engineering, Lanzhou University of Technology, Lanzhou 730050, China \\ Correspondence should be addressed to Hui Quan; quanh2010@163.com
}

Received 27 November 2020; Revised 6 February 2021; Accepted 20 March 2021; Published 30 March 2021

Academic Editor: Ling Zhou

Copyright (c) 2021 Hui Quan et al. This is an open access article distributed under the Creative Commons Attribution License, which permits unrestricted use, distribution, and reproduction in any medium, provided the original work is properly cited.

\begin{abstract}
We design optimization on the overall blade structure of a vortex pump conducted by using the orthogonal test method to clarify the matching relationship of impeller and casing structures and then improve the hydraulic performance of the vortex pump. Based on two different impeller structures of forward-deflecting (denoted as $R_{1}-F_{2}$ ) and backward-deflecting (denoted as $F_{1}-R_{2}$ ), key parameters describing the impeller structure are calculated through optimization for the objective function of hydraulic efficiency by means of orthogonal tests and computational fluid dynamic simulations. Optimization computations show that the forward-deflecting blade impeller is superior to the backward-deflecting one. Model test of the optimized vortex pump is carried out calculating the error from the comparison of pump efficiencies calculated by model test and numerical simulation is calculated to be less than $6 \%$. The experimental verification shows that the flow simulation has some errors. The weight of structure parameters such as the blade installation angle $(\alpha)$, the blade deflecting angle $(\beta)$, the position of blade deflecting point $(L)$, the radius $(r)$ of smoothing arc at the deflecting point, the wedge type $(W)$ of blade, to the lift head, the flow rate, and the efficiency of the pump is investigated, through multiparameter optimizations. Visualization observation of flows in the model pump consisted of a back-placed impeller and a front vaneless chamber is further performed. The characteristic of vortex formation predicted by flow simulation agrees with the result of visualization observation. The above results demonstrate that the optimum impeller type of vortex pump is forward-deflecting blade impeller. The optimum combination of the key structure parameters is that the deflection angle of the blade inlet $(\alpha)$ equals $30^{\circ}$, the position of blade deflecting point $l_{M}=2 / 3 \mathrm{~L}$, the chamfering radius $(r)$ at the deflecting point $r=3 \mathrm{~mm}$, and the best wedge type is axial deflecting blade.
\end{abstract}

\section{Introduction}

Vortex pumps used for transporting suspensions such as pulp solutions with short fibers are quite different to the traditional pumps in pump structure and flow pattern [1]. As shown in Figure 1, the main structural characteristic of vortex pump is that an impeller is placed behind the volute casing and a vaneless chamber is arranged in front of the impeller. With rotating of the impeller, a throughflow and circulation flow are formed, respectively, in the back-placed rotational flow path and the vaneless chamber in front of the impeller. This unique pump is simple in structure, easy to manufacture, and stable in operation and has good performance in nonclogging and special advantages in pumping complex two-phase fluid media containing impurities, such as garbage and short fibers.
In 1954, the first vortex pump with WEMCO was developed by Western Machine Company. Then the company Sterbery-Flygt in Sweden trial-produced the first vortex pump [2], and Rutschi published the first literature on vortex pump [3]. In the light of internal flow characteristics and mechanism of vortex pump, Schivley et al. established a flow model based on the experiments of predecessors [4-6]. Cai carried out an experimental study on 6J35 vortex pump [7]. In the following days, research results of modern vortex pump have been published continuously under the persistent efforts of numerous scientific researchers.

At present, model test is the most accurate method to optimize the design of vortex pump. In the optimization process, it is a necessity to carry out model tests of combination schemes involving multiple factors, which will take a lot of time. Zheng and Cheng studied the influence 


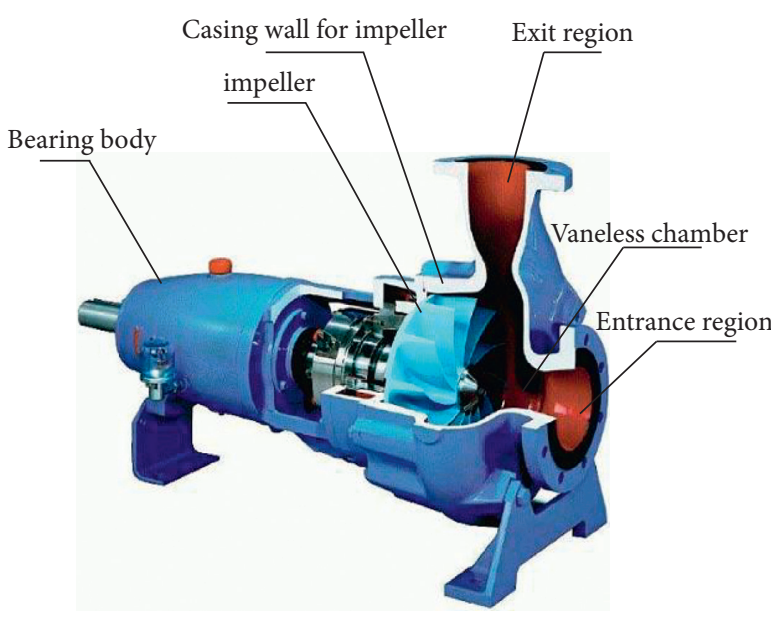

(a)

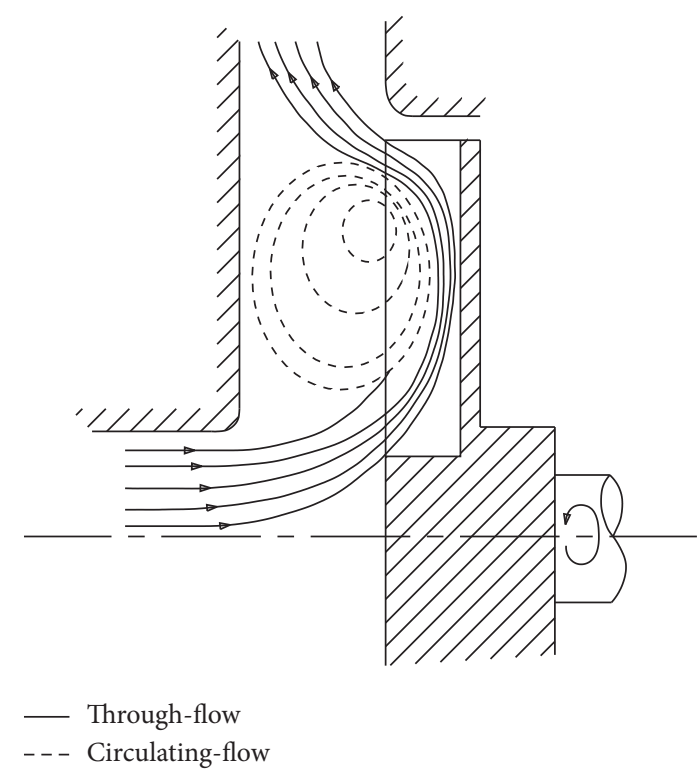

(b)

Figure 1: Schematic diagram of vortex pump. (a) Pump structure. (b) Internal flow pattern.

structural parameters for the performance of vortex pump [8]. In 2006, Shi et al. carried out a specific study on the internal flow characteristics of the vortex pump [9]. Through the method of test, analysis, and statistics, Sha deduced the equation of the least square solution for the empirical coefficient, which is suitable for the centrifugal slurry pump and vortex pump [10]. And PIV technology is applied by Quan et al. to evaluate the performance of solid-liquid twophase flow pump, with the energy conversion law of the solid-liquid two-phase flow pump summarized [11].

The vortex pump does work on fluid when its impeller rotates, and according to $\mathrm{Zhu}$ et al., the circulation flow is formed in the vaneless chamber in front of the impeller [12-16]. A throughflow is directed through the impeller. However, the influence of impeller structure on the performance of vortex pump still needs to be further investigated. What is more, only one structure type could be changed each time while the other ones keep fixed in the numerical calculation and test, rarely giving thought to the influence of changing two or more types for the performance of the vortex pump at the same time [16-19]. As an efficient method of dealing with multiple parameter optimization design, orthogonal test has been widely used in design optimization of pump for effectively solving the problem that the periodic time of model test is too long [20-25]. In this paper, the method of orthogonal test is applied to multiparameter design of a vortex pump to clarify the matching relationship of impeller and casing structures and improve the hydraulic performance of the vortex pump [26-28]. Its basic characteristic is to use partial test instead of comprehensive test, and it is an efficient, fast, and economical experimental design method $[29,30]$. By studying and summarizing the previous research results on the blade of the vortex pump, it can be found that the most important factors of the blade deflecting of the vortex pump mainly include the position of the blade deflecting point, the angle of the blade inlet and outlet, and the thickness and width of the blade [31-35].

\section{Model of Vortex Pump and Design Parameters}

2.1. Geometry Parameters of Impeller. Optimization design of hydraulic is carried out for the main flow components of the vortex pump, including the deflection angle blade at the inlet $(\alpha)$, the chamfering radius at the blade deflecting point $(r)$, the position of blade deflecting point $(M)$, and the wedge $(W)$ of deflecting blade. The main design parameters of horizontal 150WX-200-20 vortex pump are the rated flow $Q=200 \mathrm{~m}^{3} / \mathrm{h}$, the rated head $H=20 \mathrm{~m}$, the rated speed $n=1450 \mathrm{r} / \mathrm{min}$, the specific speed $n_{s}=132$, the rated efficiency $\eta=50 \%$, and the shaft power $\mathrm{P}=21.952 \mathrm{~kW}$. The geometric parameters of the impeller obtained by the hydraulic design with the parameters of vortex pump are shown in Table 1.

2.2. Geometry and Structure of Volute. There are many kinds of structure of volute, such as spiral, quasi-spiral, annular, and circular. And the annular volute is selected according to the structure design and hydraulic design of impeller, with the main geometric parameters in volute of vortex pump obtained and shown in Table 2 .

The two-dimensional structure model of vortex pump can be obtained from the hydraulic design of the impeller and volute, as shown in Figure 2.

2.3. Structural Type and Design Parameters of Blade. The type of blade has certain relations with the performance of vortex pump. There are three kinds of blade: the straight blade, the 
TABLE 1: Dimension parameters of impeller.

\begin{tabular}{lcc}
\hline Impeller outer diameter $\left(D_{2} / \mathrm{mm}\right)$ & Blade width $(\mathrm{b} / \mathrm{mm})$ & Blade number $(N)$ \\
\hline 250 & 60 & 10
\end{tabular}

TABLE 2: Geometric parameters of volute.

\begin{tabular}{lccccc}
\hline $\begin{array}{l}\text { Base diameter } \\
\left(D_{3} / \mathrm{mm}\right)\end{array}$ & $\begin{array}{c}\text { Leafless cavity } \\
\text { width }(L / \mathrm{mm})\end{array}$ & $\begin{array}{c}\text { Clearance between outer diameter of } \\
\text { impeller and shell }(e / \mathrm{mm})\end{array}$ & $\begin{array}{c}\text { Inlet diameter } \\
\left(D_{1} / \mathrm{mm}\right)\end{array}$ & $\begin{array}{c}\text { Outlet diameter } \\
\left(D_{4} / \mathrm{mm}\right)\end{array}$ & $\begin{array}{c}\text { Diffusion length of } \\
\text { volute }\left(L_{d} / \mathrm{mm}\right)\end{array}$ \\
\hline 200 & 70 & 30 & 130 & 130 & 300 \\
\hline
\end{tabular}

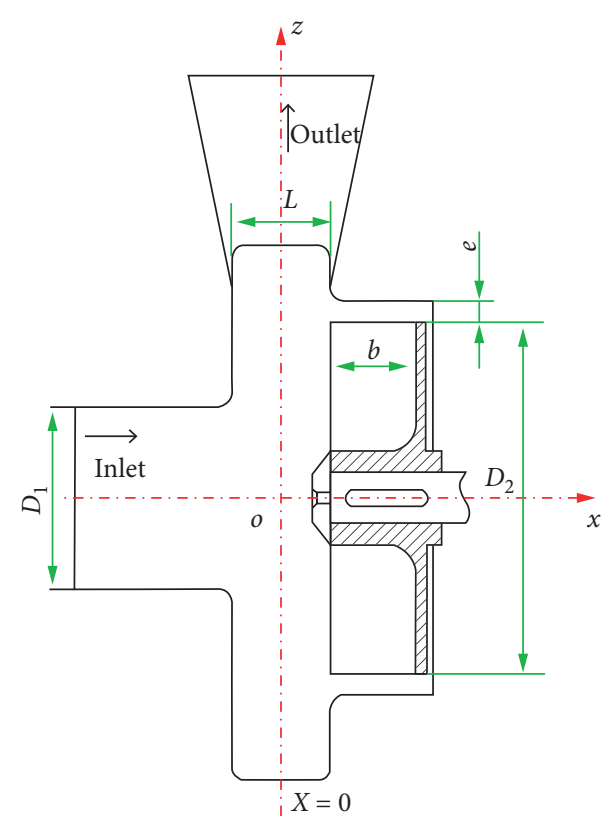

(a)

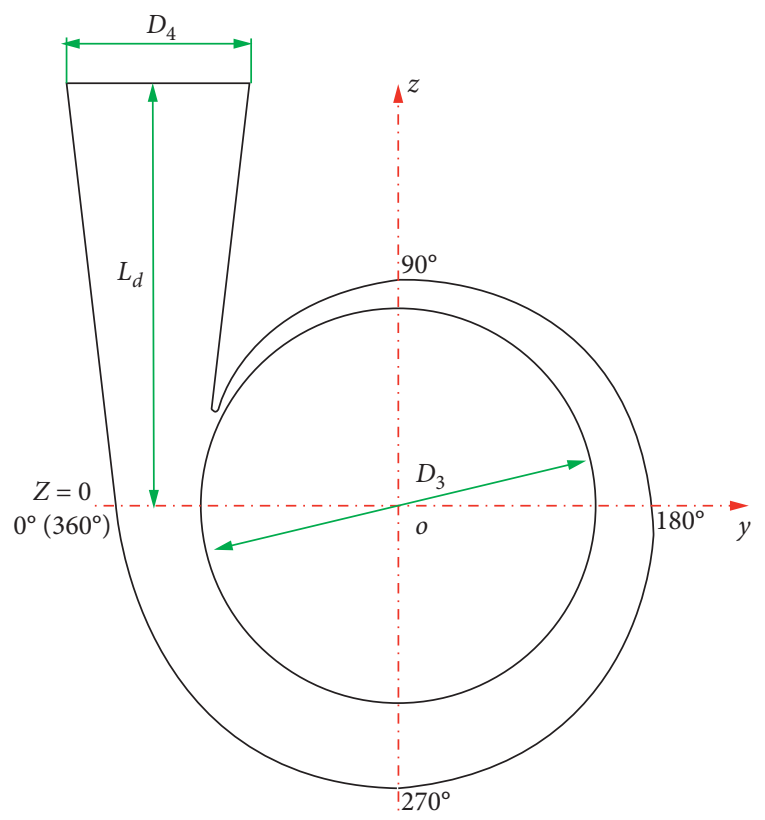

(b)

Figure 2: 150WX-200-20 structure of vortex pump.

deflection blade, and the curved blade. And the deflection blade is divided into two kinds: forward-deflecting $\left(R_{1}-F_{2}\right)$ and backward-deflecting $\left(F_{1}-R_{2}\right)$. A geometry parameter of the deflection blade is shown in Figure 3. The distance $l_{M}$ from the leading edge of the blade to the deflection point $(M)$ is set to be $2 / 3,3 / 4$, and $4 / 5$ of the blade length, respectively. The angle between the blade profile and $y$-axis is recorded as alpha and set as the inclination angle of the first section. If the deflection direction of the blade profile is the same as the rotation direction, it is $F_{1}(\alpha)$, and vice versa, it is $R_{1}(\alpha) . F_{2}$ $(\beta)$ and $R_{2}(\beta)$ are defined in the same way. So these two kinds of blade structure for the vortex pump are obtained: forward-deflecting $\left(R_{1}-F_{2}\right)$ and backward-deflecting $\left(F_{1}-R_{2}\right)$.

2.4. Structure of Blade Wedge. Considering the improvement of efficiency, it is beneficial to reduce the thickness of blade. Design a wedge blade for example, which could not only reduce the eddy loss at the leading edge of the blade but also increase the head and efficiency of vortex pump. In this paper, mainly three different blade wedge types, axial wedge $(W, a)$, radial wedge $(W, b)$, and reverse wedge $(W, c)$, shown in Figure 4 are considered in pump design optimization.

2.5. Domain and Mesh of Vortex Pump. According to the hydraulic design and structural design of the vortex pump, the model of 3D numerical simulation can be established and divided by the structure mesh, as shown in Figure 5.

2.6. Validation of Mesh Density Independence. From the perspective of fluid simulation, when the flow model is meshed, the smaller the volume of the grid, the bigger the number of grids, so that the calculation results of the fluid will be accurate and the error will be smaller. In the first mock exam, when the number of grids and the mesh volume reach a certain value, the number of grids will not increase significantly, but the computation time will increase. The first mock exam is divided into 5 sets of different grids. The grid density of scheme 1 to scheme 5 is analyzed in 


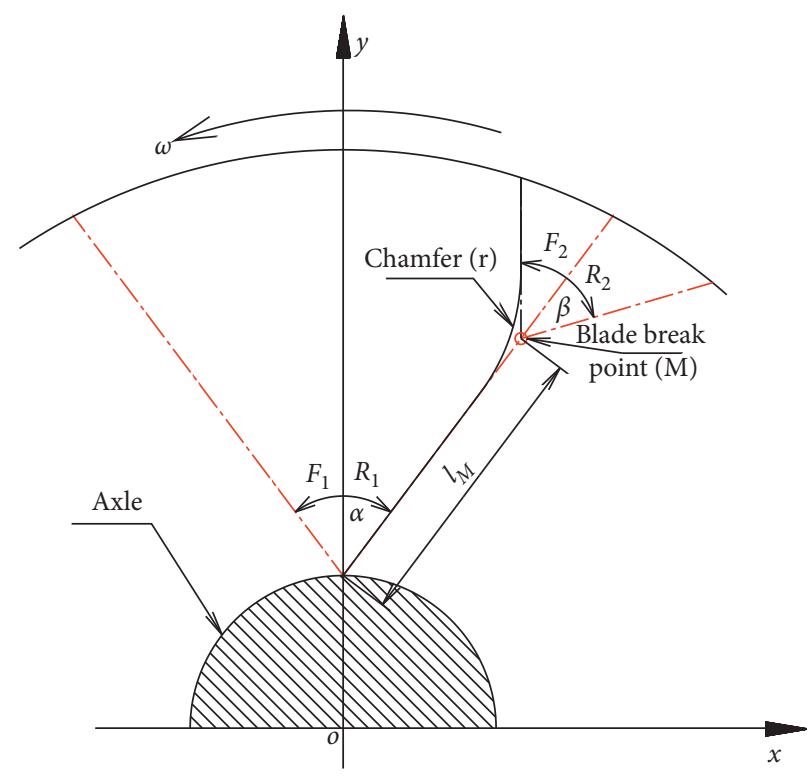

Figure 3: Structure of deflection blade.

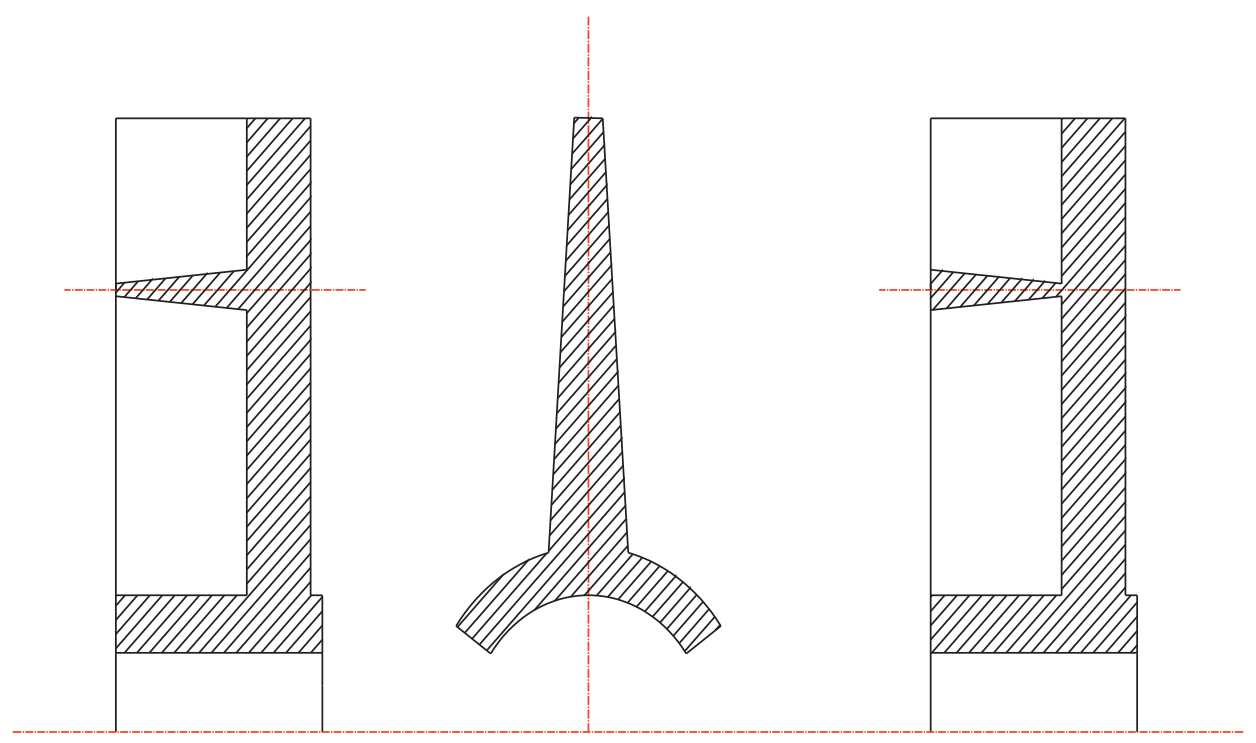

FIGURE 4: Structure of blade wedge.

accordance with the principle of sequential increase, and the number of grids is shown in Table 3.

The first mock exam is based on the 5 sets of structural mesh numbers in Table 3 . When the rated operating point $Q=200 \mathrm{~m}^{3} / \mathrm{h}$, the 5 sets of grids of the same model are simulated. Finally, the data are extracted to analyze the influence of grid density on the head performance of the vortex pump. According to the grid number and the head data calculated by the vortex pump, the influence of grid number on its hydraulic performance can be judged. The specific data can be obtained by numerical calculation, and the histogram can be established by the data between the head of the vortex pump and the number of grids. The relationship between the number of grids and the head of the vortex pump can be clearly observed, as shown in Figure 6.
According to the relationship shown in the histogram in Figure 5, there is a relationship between the head performance and the number of grids. Through observation, it is not that the more the number of grids, the better the head performance of the vortex pump.

With the increase of the number of grids, the calculated head value of the vortex pump is improved. When the total number of grids of the vortex pump reaches 3.62 million, its hydraulic performance is the best. After that, increasing the number of grids has no effect on the improvement of the hydraulic performance, and the hydraulic head of the vortex pump decreases slightly. The calculation shows that the error caused by the number of grids is less than $3 \%$, so it can be judged that the number of grids and the division method have no significant effect on the performance of the vortex 

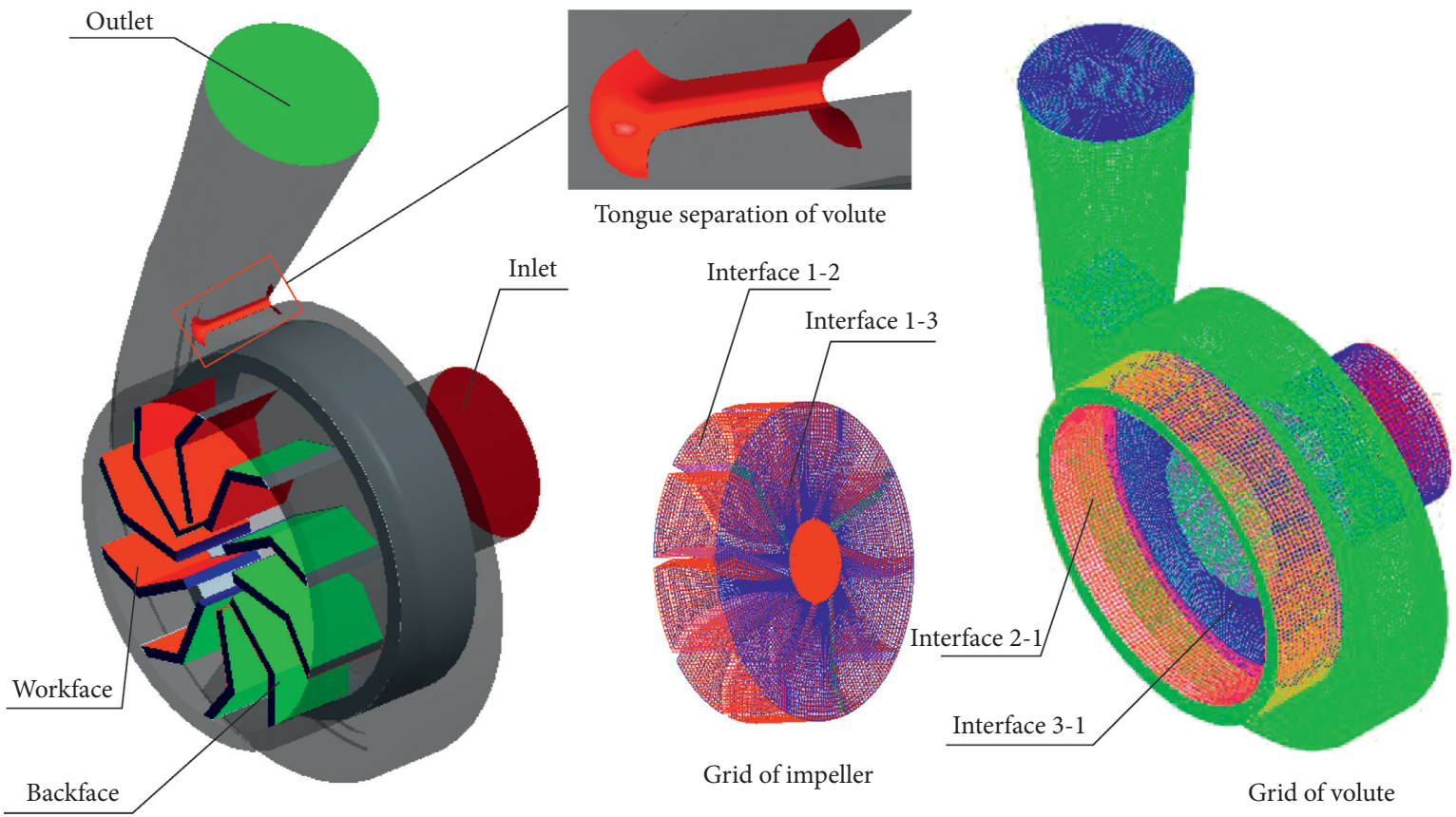

3D model of vortex

Figure 5: Three-dimensional geometry domain of vortex pump.

Table 3: Design of grid quantity scheme.

\begin{tabular}{lcccc}
\hline $\begin{array}{l}\text { Number of grids } \\
\text { Part name }\end{array}$ & Scheme 1 & Scheme 2 & Scheme 3 & Scheme 4 \\
\hline Impeller & 486356 & 583847 & 700552 & 840822 \\
Volute & 2031146 & 2437475 & 2924050 & 3509920 \\
Assembled part & 2517502 & 3021322 & 3624602 & 4350742 \\
\hline
\end{tabular}

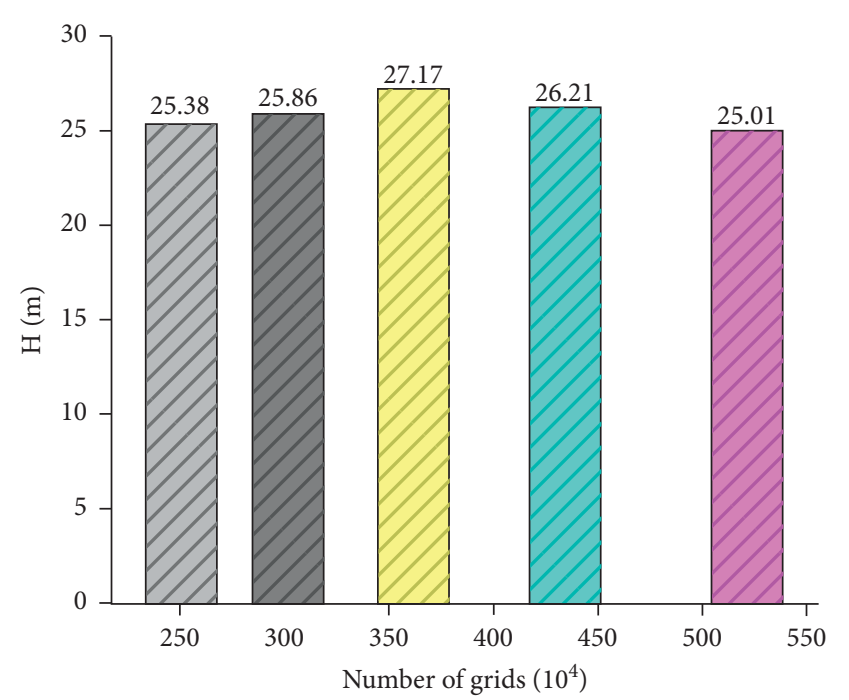

Figure 6: Mesh density independence from the calculation results.

pump studied in this paper, which can be ignored. After comprehensive consideration, the grid number and grid generation method of scheme 3 are adopted.
2.7. Method of Numerical Calculation and Boundary Conditions. In this optimization process, the CFD software is used to model and solve the numerical problems. First, the water body model of the impeller and volute of the vortex pump is built by Pro-E. Secondly, the water body of the vortex pump is meshed by ICEM 15.0. Then the simulation calculation is carried out in Fluent 15.0. After the calculation is completed, the postprocessing is carried out by CFD-Post 15.0. We adopt algorithm of SIMPLE, the discrete format is set to second-order upwind, and the residual accuracy is $10^{-6}$. The relative reference coordinate system is adopted in the simulation of vortex pump, with the rotating coordinate system used in the impeller passage. And the rotation speed of the impeller is $1450 \mathrm{r} / \mathrm{min}$. The velocity with an irrotational flow is set at the inlet of the vortex pump, and the fluid boundary condition at the outlet of the vortex pump is set to the free outflow fluid. The three-dimensional steady-state Reynolds-averaged Navier-Stokes equations and RNG $k-\varepsilon$ turbulence model equations are used in mathematical model calculation. The static coordinate system is taken in the flow passage of volute. And the internal flow of vortex pump is considered as a complex three-dimensional incompressible turbulent flow, which rotates around a fixed rotating shaft at a constant angular velocity. In the coincidence of the 
interference surface produced by the impeller dynamic coordinate system and volute static coordinate system, the same boundary is shared among adjacent domains. It is not difficult to generate meshes at this junction, and the effects of the interaction from the upstream and downstream are determined by the parameter selection. However, when dealing with the overlap of interference surfaces between the dynamic and static subdomains, it is necessary to add computing stations artificially. Furthermore, the generation of grids at this junction is much more complex, and the influences of the interaction from the upstream and downstream are decided by the interaction of grids. The condition of the volute wall is static without slip, and that of the impeller wall is motion without slip.

\section{Design Plans and Orthogonal Tests}

3.1. Selection of Factor Level for Design Parameters. The analysis process of orthogonal test design includes five basic steps: determining all the main factors and levels, designing an appropriate orthogonal table, listing test schemes and test results, carrying out range analysis and regression analysis on the results of orthogonal test design, and determining the optimal or less optimal combination of factors. In this paper, the hydraulic performance of vortex pump is optimized by introducing four factors: the deflection angle blade at the inlet $(\alpha)$, the chamfering radius $(r)$ at the blade deflecting point, the position of blade deflecting point $(M)$, and the wedge $(W)$ of deflecting blade. Each factor takes three levels. According to the principle of orthogonal method, four factors and three levels are selected to design a level table for calculation factors. These four different factors are represented by $A, B, C$, and $W$, respectively. The factor level table is shown in Table 4.

In Table 3, $A_{1}, A_{2}$, and $A_{3}$ represent deflection angle of blade inlet $(\alpha)$ of $30^{\circ}, 45^{\circ}$, and $60^{\circ}$, respectively. $B_{1}, B_{2}$, and $B_{3}$ represent at $2 / 3 \mathrm{~L}, 3 / 4 \mathrm{~L}$, and $4 / 5 \mathrm{~L}$ length of blade, respectively. $C_{1}, C_{2}$, and $C_{3}$ represent the chamfering radius size $(r)$ deflection point position of blade of $3 \mathrm{~mm}, 4 \mathrm{~mm}$, and $5 \mathrm{~mm}$, respectively. $W_{1}, W_{2}$, and $W_{3}$ represent the type of deflection blade with axial wedge, radial wedge, and antiaxial wedge, respectively. All structures are shown in Figure 7.

\subsection{Configuration of Blade Structure Parameters.} According to the structural of blade changes of vortex pump selected above, four parameters and three different levels of each factor are determined. The number of tests can be squeezed into nine combinations. And each combination just needs simulation with seven different working conditions. So, it is important to select an appropriate orthogonal table. In the end, $L_{9}\left(3^{4}\right)$ orthogonal table is selected for vortex pump through the orthogonal test design and situations in practice. Nine kinds of configuration schemes can be obtained through these three steps of the orthogonal table design, the factor level design, and the table head design, as shown in Table 5.

The concept of blade structure on vortex pump based on the orthogonal test is put forward to optimize the internal flow state and improve the efficiency of vortex pump. Four main blade structures of the vortex pump are selected to control the flow state. On account of the orthogonal test method and the numerical simulation analysis theory, the optimal configuration relationship between the blade structure types and the flow states in the vortex pump is expected to be found.

\section{Results and Discussion}

4.1. Range Analysis of Test Results. The range analysis, dealing with orthogonal test data, is a mathematic method of finding an optimal scheme by calculating the range of quality indicators. The larger the range is, the greater the effect of the change of this factor level on the quality indicator is, which means this factor is much more important, and vice versa. The data at the highest efficiency point of each orthogonal test scheme is shown in Table 6 .

The range analysis of the flow and head at the maximum efficiency point is shown in Table 7. According to the magnitude of the range, the important order of relevant factors that have influence on the flow rate of forwarddeflecting blade at the maximum efficiency point is as follows: the deflection angle of blade inlet $(\alpha)$, the position of blade deflection point $(M)$, the chamfering radius size $(r)$ of blade deflection point, and the deflection blade types of wedge $(W)$, with the optimal combination being $A_{2} B_{2} C_{1} W_{2}$. Meanwhile, the important order of relevant factors that affect the flow rate of backward-deflecting blade at the maximum efficiency point is as follows: the deflection angle of blade inlet $(\alpha)$, the deflection blade types of wedge $(W)$, the position of blade deflection point $(M)$, and the chamfering radius size $(r)$ of blade deflection point, with the optimal combination being $A_{1} / A_{2} B_{1} C_{3} W_{1} / W_{3}$. The important order of relevant factors having influence on the head of forward-deflecting blade at the maximum efficiency point is as follows: the deflection blade types of wedge $(W)$, the position of blade deflection point $(M)$, the deflection angle of the blade inlet $(\alpha)$, and the chamfering radius size $(r)$ of the blade deflection point, with the optimal combination being $A_{1} B_{3} C_{3} W_{2}$. Meanwhile, the important order of relevant factors affecting the head of backward-deflecting blade at the maximum efficiency point is as follows: the position of blade deflection point $(M)$, the deflection blade types of wedge $(W)$, the deflection angle of blade inlet $(\alpha)$, and the chamfering radius size $(r)$ of blade deflection point, with the optimal combination being $A_{1} B_{3} C_{2} W_{1}$.

The range analysis of the efficiency and shaft power at the maximum efficiency point is shown in Table 8. According to the magnitude of the range, the important order of relevant factors that have influence on the efficiency of forwarddeflecting blade at the maximum efficiency point is as follows: the deflection blade types of wedge $(W)$, the chamfering radius size $(r)$ of blade deflection point, the position of blade deflection point $(M)$, and the deflection angle of blade inlet $(\alpha)$, with the optimal combination being $A_{3} B_{1} C_{1} W_{1}$. Meanwhile, the important order of relevant factors that affect the efficiency of backward-deflecting blade maximum efficiency point is as follows: the deflection angle of blade 
TABLe 4: Factor level of different design parameters.

\begin{tabular}{lcccc}
\hline \multirow{2}{*}{ Level } & \multicolumn{2}{c}{ Factors } & & \\
& Deflection angle of blade inlet $(\alpha)$ & Deflection point position $(M)$ & Chamfer $(r)$ & Wedge $(W)$ \\
\hline 1 & $A_{1}\left(30^{\circ}\right)$ & $B_{1}(2 / 3 \mathrm{~L})$ & $C_{1}(3 \mathrm{~mm})$ & $W_{1}(\mathrm{axial})$ \\
2 & $A_{2}\left(45^{\circ}\right)$ & $B_{2}(3 / 4 \mathrm{~L})$ & $C_{2}(4 \mathrm{~mm})$ & $W_{2}(\mathrm{radial})$ \\
3 & $A_{3}\left(60^{\circ}\right)$ & $B_{3}(4 / 5 \mathrm{~L})$ & $C_{3}(5 \mathrm{~mm})$ & $W_{3}(\mathrm{reverse})$ \\
\hline
\end{tabular}

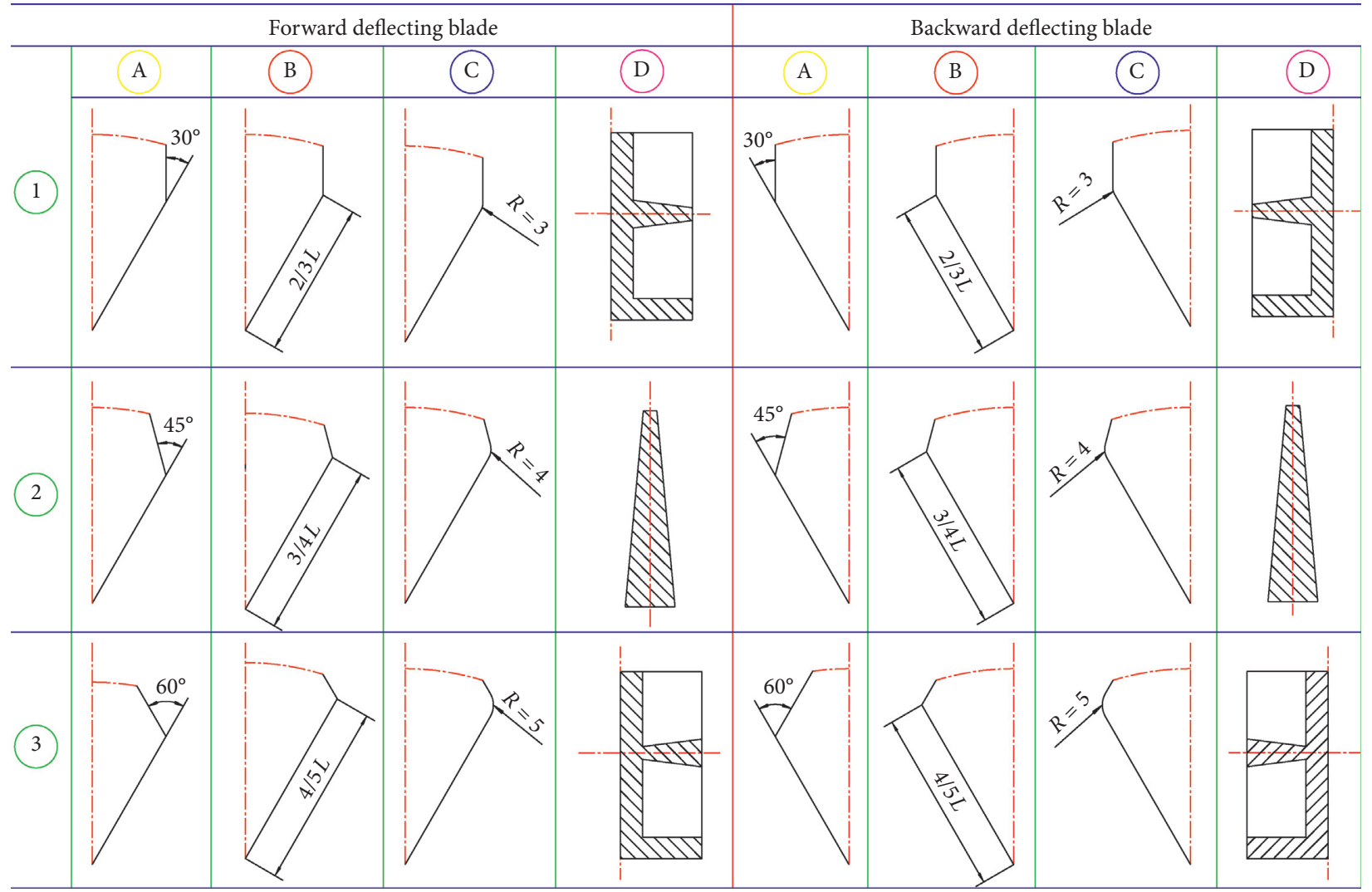

FIGURE 7: Structure of different blade types.

TABLE 5: Configuration plan of design parameters.

\begin{tabular}{|c|c|c|c|c|}
\hline \multirow{2}{*}{ Level } & \multicolumn{4}{|c|}{ Factors } \\
\hline & Deflection angle of blade inlet $(\alpha)$ & Deflection point position $(M)$ & Chamfer $(r)$ & Wedge $(W)$ \\
\hline 1 & $A_{1}\left(30^{\circ}\right)$ & $B_{1}(2 / 3 \mathrm{~L})$ & $C_{1}(3 \mathrm{~mm})$ & $W_{1}($ axial $)$ \\
\hline 2 & $A_{1}\left(30^{\circ}\right)$ & $B_{2}(3 / 4 \mathrm{~L})$ & $C_{2}(4 \mathrm{~mm})$ & $W_{2}($ radial $)$ \\
\hline 3 & $A_{1}\left(30^{\circ}\right)$ & $B_{3}(4 / 5 \mathrm{~L})$ & $C_{3}(5 \mathrm{~mm})$ & $W_{3}$ (reverse) \\
\hline 4 & $A_{2}\left(45^{\circ}\right)$ & $B_{1}(2 / 3 \mathrm{~L})$ & $C_{2}(4 \mathrm{~mm})$ & $W_{3}$ (reverse) \\
\hline 5 & $A_{2}\left(45^{\circ}\right)$ & $B_{2}(3 / 4 \mathrm{~L})$ & $C_{3}(5 \mathrm{~mm})$ & $W_{1}($ axial $)$ \\
\hline 6 & $A_{2}\left(45^{\circ}\right)$ & $B_{3}(4 / 5 \mathrm{~L})$ & $C_{1}(3 \mathrm{~mm})$ & $W_{2}$ (radial) \\
\hline 7 & $A_{3}\left(60^{\circ}\right)$ & $B_{1}(2 / 3 \mathrm{~L})$ & $C_{3}(5 \mathrm{~mm})$ & $W_{2}($ radial $)$ \\
\hline 8 & $A_{3}\left(60^{\circ}\right)$ & $B_{2}(3 / 4 \mathrm{~L})$ & $C_{1}(3 \mathrm{~mm})$ & $W_{3}$ (reverse) \\
\hline 9 & $A_{3}\left(60^{\circ}\right)$ & $B_{3}(4 / 5 \mathrm{~L})$ & $C_{2}(4 \mathrm{~mm})$ & $W_{1}($ axial $)$ \\
\hline
\end{tabular}

inlet $(\alpha)$, the position of blade deflection point $(M)$, the deflection blade types of wedge $(W)$, and the chamfering radius size $(r)$ of blade deflection point, with the optimal combination being $A_{3} B_{1} C_{2} W_{1}$. The important order of relevant factors having influence on the shaft power of forward-deflecting blade maximum efficiency point is as follows: the deflection angle of blade inlet $(\alpha)$, the position of blade deflection point $(M)$, the chamfering radius size $(r)$ of 
TABLE 6: Test results of the highest efficiency point.

\begin{tabular}{|c|c|c|c|c|c|c|c|c|}
\hline \multirow{2}{*}{ Test serial number } & \multicolumn{4}{|c|}{ Forward-deflecting blade } & \multicolumn{4}{|c|}{ Backward-deflecting blade } \\
\hline & $Q\left(\mathrm{~m}^{3} / \mathrm{h}\right)$ & $H(\mathrm{~m})$ & $\mathrm{H}(\%)$ & $P(\mathrm{~kW})$ & $Q\left(\mathrm{~m}^{3} / \mathrm{h}\right)$ & $H(\mathrm{~m})$ & $\eta(\%)$ & $P(\mathrm{~kW})$ \\
\hline 1 & 200 & 26.34 & 72.24 & 0.87 & 200 & 24.04 & 71.33 & 0.84 \\
\hline 2 & 200 & 24.41 & 68.03 & 0.88 & 160 & 24.14 & 69.20 & 0.69 \\
\hline 3 & 200 & 24.98 & 67.98 & 0.85 & 200 & 23.92 & 66.81 & 0.77 \\
\hline 4 & 200 & 23.44 & 70.56 & 0.91 & 200 & 23.06 & 68.55 & 0.85 \\
\hline 5 & 240 & 24.50 & 70.24 & 1.05 & 200 & 23.78 & 70.32 & 0.76 \\
\hline 6 & 240 & 24.05 & 69.18 & 1.04 & 160 & 23.94 & 67.62 & 0.62 \\
\hline 7 & 200 & 24.79 & 68.28 & 0.93 & 160 & 22.94 & 69.10 & 0.61 \\
\hline 8 & 240 & 21.93 & 69.81 & 1.05 & 160 & 23.19 & 67.34 & 0.64 \\
\hline 9 & 200 & 26.18 & 71.94 & 0.90 & 160 & 25.09 & 71.16 & 0.63 \\
\hline
\end{tabular}

TABLe 7: Analysis of the flow rate and head at the maximum efficiency point.

\begin{tabular}{|c|c|c|c|c|c|c|c|c|c|}
\hline \multirow{2}{*}{\multicolumn{2}{|c|}{$\begin{array}{c}\text { Blade types } \\
\text { Index }\end{array}$}} & \multicolumn{4}{|c|}{ Forward-deflecting blade } & \multicolumn{4}{|c|}{ Backward-deflecting blade } \\
\hline & & $A$ & $B$ & C & $W$ & $A$ & $B$ & C & $W$ \\
\hline \multirow{7}{*}{ Q } & $K_{1}$ & 600.00 & 600.00 & 680.00 & 640.00 & 560.00 & 560.00 & 520.00 & 560.00 \\
\hline & $K_{2}$ & 680.00 & 680.00 & 600.00 & 680.00 & 560.00 & 520.00 & 520.00 & 480.00 \\
\hline & $K_{3}$ & 640.00 & 640.00 & 640.00 & 640.00 & 480.00 & 520.00 & 560.00 & 560.00 \\
\hline & $\bar{K}_{2}$ & 200.00 & 200.00 & 226.67 & 213.33 & 186.67 & 186.67 & 173.33 & 186.67 \\
\hline & $\bar{K}_{2}$ & 226.67 & 226.67 & 200.00 & 226.67 & 186.67 & 173.33 & 173.33 & 160.00 \\
\hline & $\bar{K}_{3}^{2}$ & 213.33 & 213.33 & 213.33 & 213.33 & 160.00 & 173.33 & 186.67 & 186.67 \\
\hline & $R$ & 26.67 & 26.67 & 26.67 & 13.34 & 26.67 & 13.34 & 13.34 & 26.67 \\
\hline \multirow{7}{*}{$H$} & $K_{1}$ & 75.73 & 74.57 & 72.32 & 77.02 & 72.10 & 70.04 & 71.17 & 72.91 \\
\hline & $K_{2}$ & 71.99 & 70.84 & 74.03 & 73.25 & 70.78 & 71.11 & 72.29 & 71.02 \\
\hline & $K_{3}$ & 72.90 & 75.21 & 74.27 & 70.35 & 70.37 & 72.95 & 70.64 & 70.17 \\
\hline & $\bar{K}_{1}$ & 25.24 & 24.86 & 24.11 & 25.67 & 24.03 & 23.35 & 23.72 & 24.30 \\
\hline & $\bar{K}_{2}$ & 24.00 & 23.61 & 24.68 & 24.42 & 23.59 & 23.70 & 24.10 & 23.67 \\
\hline & $\bar{K}_{3}$ & 24.30 & 25.07 & 24.76 & 23.45 & 23.46 & 24.32 & 23.55 & 23.39 \\
\hline & $R$ & 1.24 & 1.46 & 0.65 & 2.22 & 0.57 & 0.97 & 0.55 & 0.91 \\
\hline
\end{tabular}

TABLE 8: Analysis of the efficiency and shaft power at the maximum efficiency point.

\begin{tabular}{|c|c|c|c|c|c|c|c|c|c|}
\hline \multirow{2}{*}{\multicolumn{2}{|c|}{$\begin{array}{c}\text { Blade types } \\
\text { Index }\end{array}$}} & \multicolumn{4}{|c|}{ Forward-deflecting blade } & \multicolumn{4}{|c|}{ Backward-deflecting blade } \\
\hline & & $A$ & $B$ & C & $W$ & $A$ & $B$ & C & $W$ \\
\hline \multirow{7}{*}{$\eta$} & $K_{1}$ & 208.25 & 211.08 & 211.23 & 214.42 & 207.34 & 208.98 & 206.29 & 212.81 \\
\hline & $K_{2}$ & 209.98 & 208.08 & 210.53 & 205.49 & 206.49 & 206.86 & 208.91 & 205.92 \\
\hline & $K_{3}$ & 210.03 & 209.10 & 206.50 & 208.35 & 207.60 & 205.59 & 206.23 & 202.70 \\
\hline & $\bar{K}_{1}$ & 69.42 & 70.36 & 70.41 & 71.47 & 69.11 & 69.66 & 68.76 & 70.94 \\
\hline & $\bar{K}_{2}$ & 69.99 & 69.36 & 70.18 & 68.50 & 68.83 & 68.95 & 69.64 & 68.64 \\
\hline & $\bar{K}_{3}$ & 70.01 & 69.70 & 68.83 & 69.45 & 69.20 & 68.53 & 68.74 & 67.57 \\
\hline & $R$ & 0.59 & 1.00 & 1.58 & 2.97 & 0.37 & 1.13 & 0.90 & 3.37 \\
\hline \multirow{7}{*}{$P$} & $K_{1}$ & 2.60 & 2.71 & 2.96 & 2.82 & 2.30 & 2.30 & 2.10 & 2.23 \\
\hline & $K_{2}$ & 3.00 & 2.98 & 2.69 & 2.85 & 2.23 & 2.09 & 2.17 & 1.92 \\
\hline & $K_{3}$ & 2.88 & 2.79 & 2.95 & 2.81 & 1.88 & 2.02 & 2.14 & 2.26 \\
\hline & $\bar{K}_{1}$ & 0.87 & 0.90 & 0.99 & 0.94 & 0.77 & 0.77 & 0.70 & 0.74 \\
\hline & $\bar{K}_{2}$ & 1.00 & 0.99 & 0.90 & 0.95 & 0.74 & 0.70 & 0.72 & 0.64 \\
\hline & $\bar{K}_{3}$ & 0.96 & 0.93 & 0.98 & 0.94 & 0.63 & 0.67 & 0.71 & 0.75 \\
\hline & $R$ & 0.13 & 0.09 & 0.09 & 0.01 & 0.14 & 0.10 & 0.02 & 0.11 \\
\hline
\end{tabular}

blade deflection point, and the deflection blade types of wedge $(W)$, with the optimal combination being $A_{1} B_{1} C_{2} W_{3}$. Meanwhile, the important order of relevant factors affecting the shaft power of backward-deflecting blade maximum efficiency point is as follows: the deflection angle of blade inlet $(\alpha)$, the deflection blade types of wedge $(W)$, the position of blade deflection point $(M)$, and the chamfering radius size $(r)$ of blade deflection point, with the optimal combination being $A_{3} B_{3} C_{1} W_{2}$. It can be concluded that scheme 1 is the optimal combination.

For the analysis convenience, the factor level is set as the horizontal coordinate, with the average value of the index being set as the longitudinal coordinates. And the relationship between the factors and indexes is pictured in Figure 8. 


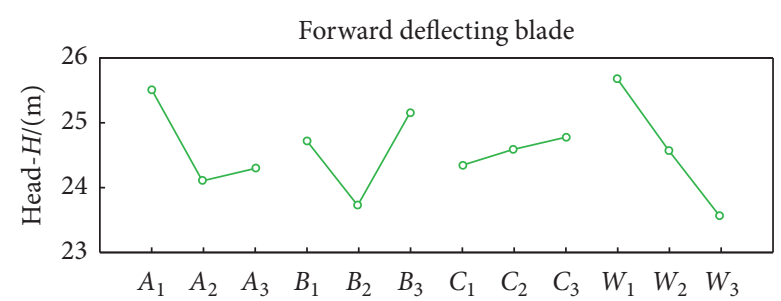

(a)

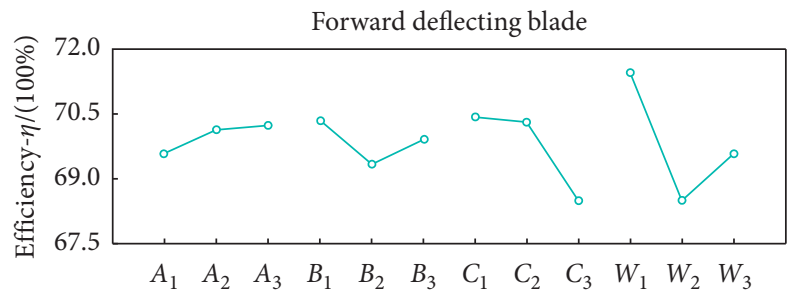

(c)

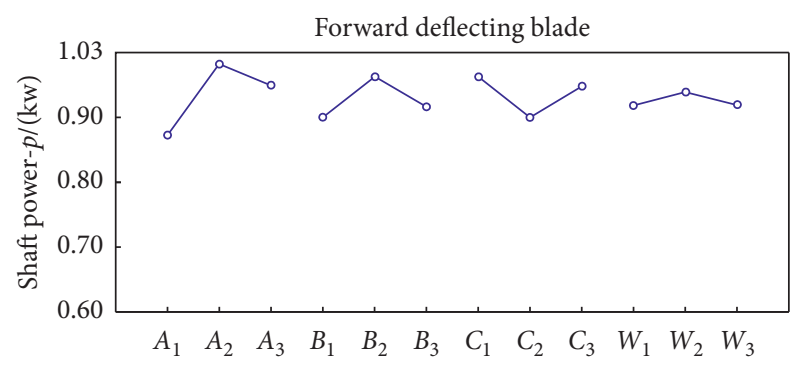

(e)

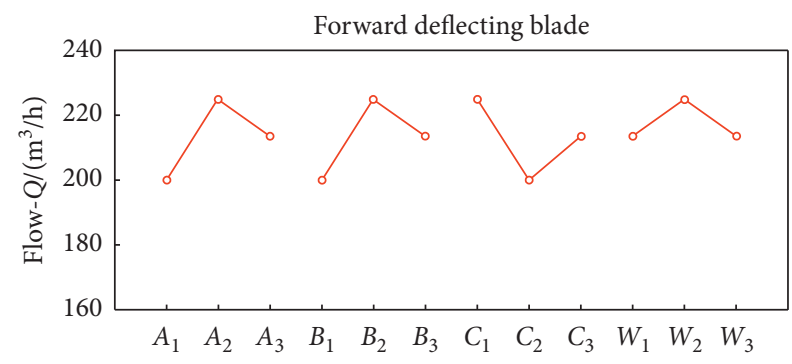

(g)

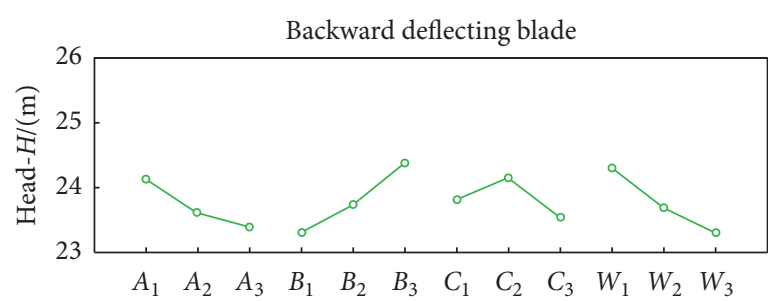

(b)

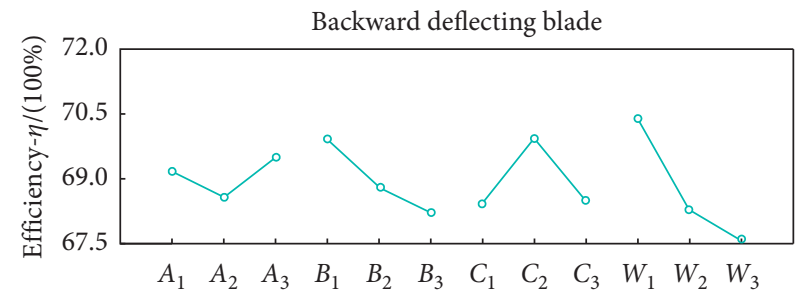

(d)

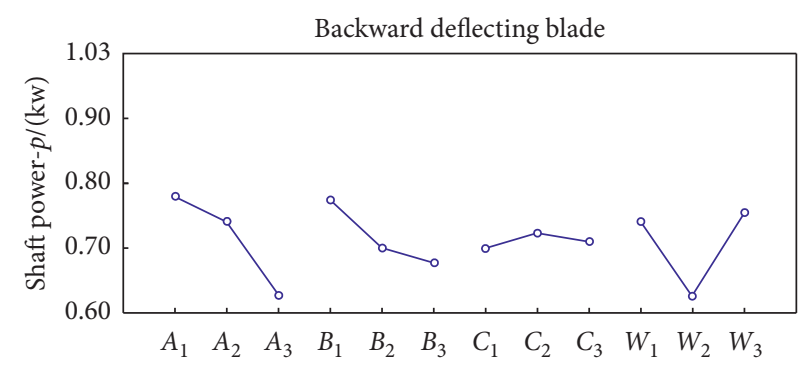

(f)

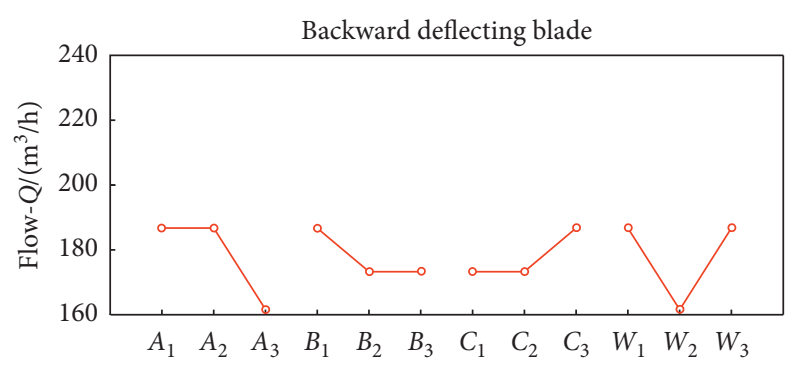

(h)

FIgURE 8: Relationship between various factors and indexes.

After comparing the optimum conditions of all indexes and weighting the optimal condition of each individual index synthetically, the most optimal parameter combination taking the optimal index of all aspects into account for the forward-deflecting blade and backward-deflecting blade is as follows: $30^{\circ}$ for the deflection angle of blade inlet $(\alpha), 2$ / $3 \mathrm{~L}$ of blade for the position of blade deflection point $(M)$, $3 \mathrm{~mm}$ for the chamfering radius size $(r)$ of blade deflection point, and the axial wedge for the deflection blade types of wedge $(W)$. After comprehensive comparison and analysis, scheme 1 with forward-deflecting blade is the optimal design. According to the magnitude of the range, the important orders of these four factors which have influence on each index are shown in Table 9.

\section{Experimental Investigation of Pump Performance}

5.1. Experiment Devices Performance Test and Internal Flow Observation. Experiments and numerical calculations are carried out respectively to verify the reliability and accuracy of vortex pump under orthogonal experimental optimization design. The open type of the test bench is used in the test schematic diagram, as shown in Figure 9. In the process of connecting the pipeline and line of the test bed, the main body includes pump body, high-speed camera, motor, speed and torque meter, frequency converter, and pressure gauge. In the process of test, we use high-speed camera to photograph the flow structure inside the vortex pump on an 
TABLE 9: Important order of factors affecting performance.

\begin{tabular}{|c|c|c|c|c|c|c|c|c|}
\hline \multirow{2}{*}{$\begin{array}{l}\text { Factors } \\
Q\left(\mathrm{~m}^{3} / \mathrm{h}\right)\end{array}$} & \multicolumn{4}{|c|}{ Forward-deflecting blade (main $\longrightarrow$ subordinate) } & \multicolumn{4}{|c|}{$\begin{array}{l}\text { Backward-deflecting blade } \\
\text { (main } \longrightarrow \text { subordinate) }\end{array}$} \\
\hline & $A$ & $B$ & $C$ & $W$ & $A$ & $W$ & $B$ & $C$ \\
\hline$H(\mathrm{~m})$ & $W$ & $B$ & $A$ & C & $B$ & $W$ & $A$ & C \\
\hline$\eta(\%)$ & $W$ & $C$ & $B$ & $A$ & $A$ & $B$ & $W$ & $C$ \\
\hline$P(\mathrm{~kW})$ & $A$ & $B$ & C & $W$ & A & $W$ & $B$ & C \\
\hline
\end{tabular}

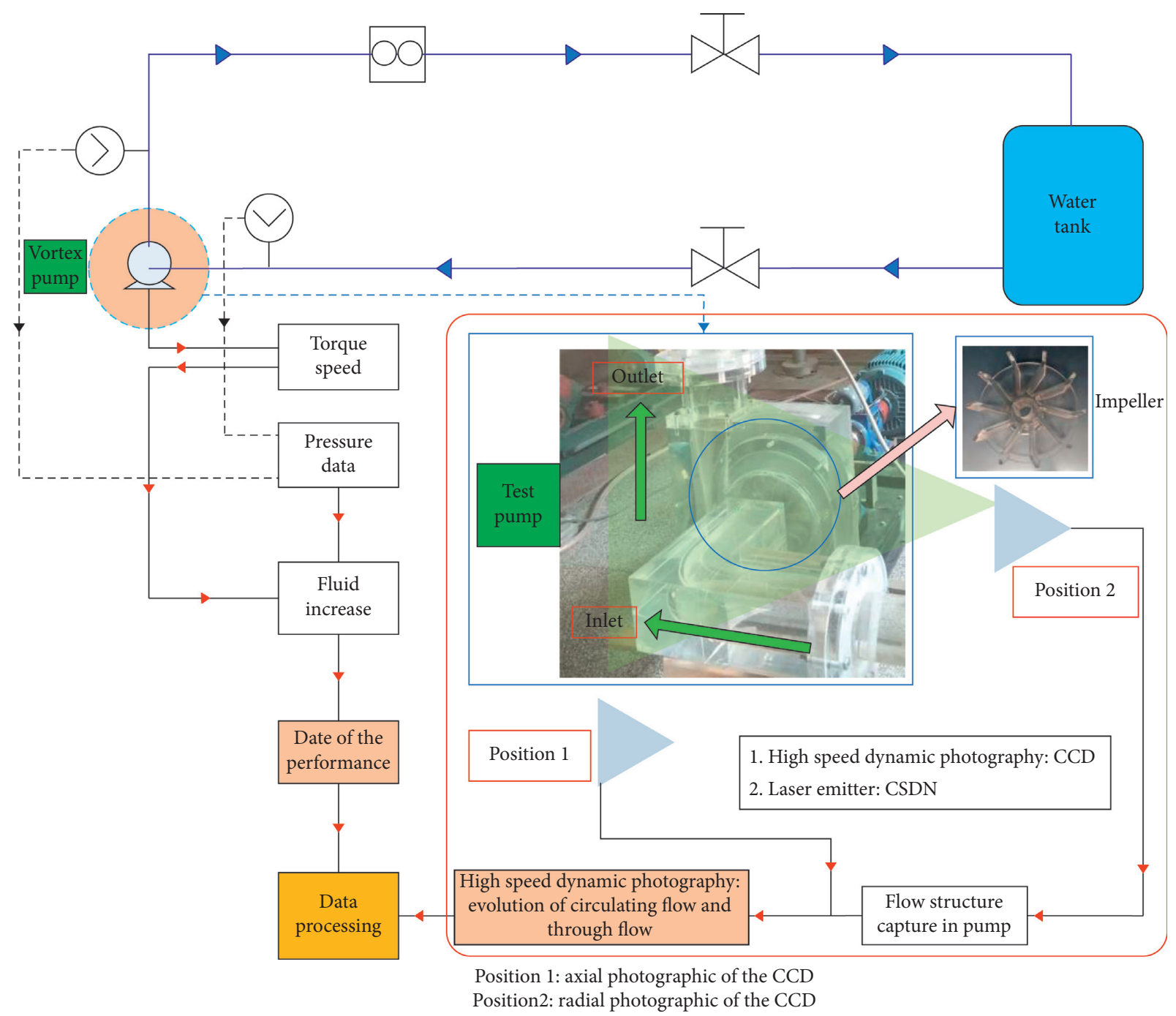

Figure 9: Performance test system.

open test bed to test and record the measured data at any time.

5.2. Comparative Analysis of Performance Pump. The most optimal scheme model which is found by optimum design is tested and calculated separately and compared with the original scheme. The hydraulic performance comparison between the optimized model and the original model is shown in Figure 10 . Head- $H_{1}$, Efficiency- $\eta_{1}$, and Power- $P_{1}$ represent the performance parameters of the calculation results of the optimization model, while $\mathrm{Head}-\mathrm{H}_{2}$,
Efficiency- $\eta_{2}$, and Power- $P_{2}$ represent the performance parameters of the calculation results of the original design model.

The analysis of numerical Figure 10 shows that, with the gradual change of vortex pump flow rate from small to large, compared with the original impeller model and the optimized impeller model calculation can be obtained: after optimization, the Head $H$ of vortex pump at each operating point is increased by $2.27 \%$, the Efficiency- $\eta$ is increased by $5.26 \%$, and the shaft Power- $P$ is reduced by $5.94 \%$. From the comparison, we can see that the hydraulic performance of optimized impeller, such as head and efficiency, has been 


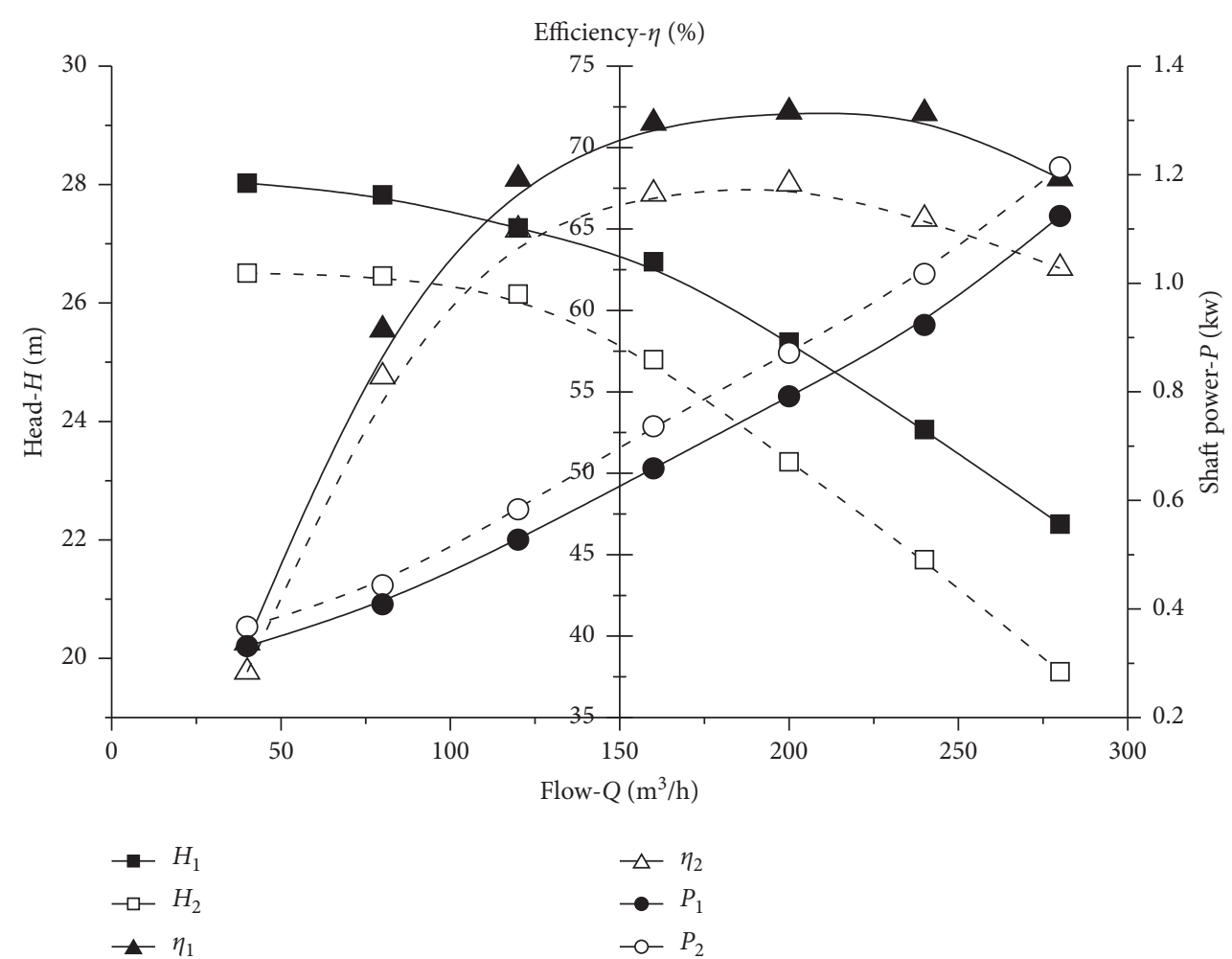

FIgURE 10: Comparison of performance curve between original model and optimization model.

significantly improved, and the performance has been improved.

\subsection{Characteristics of Internal Flow Field in Vortex Pump} Designed. Figure 11 is the comparison of the streamline and vorticity between the optimization scheme and the original one with the orthogonal experimental design.

From the streamline comparison chart in Figure 11(a), compared with the optimization scheme, the original scheme has more vortices formed by radial streamline flow. That is the reason why more energy loss is caused and the efficiency is also reduced. In addition, the radius of streamline vortices in the optimization scheme is much larger generally than the one in the original one and the streamline of optimization scheme is much smoother. This leads to less energy loss. From the vorticity comparison chart in Figure 11(b), it can be seen that the vorticity scattered much more evenly in the optimization model than the original one. Compared with the vorticity of the original design model without optimization, the area of vorticity between the passages of the original design model occupies half of the whole passage of the impeller, while the area of vorticity between the passages of the optimized one decreases significantly. The size of the vorticity area has a direct impact on the hydraulic performance of the impeller. The reduction of the vorticity area represents the effectiveness of the optimization, and the distribution of vorticity between the passages of the optimized impeller model is more uniform, which is conducive to the improvement of the hydraulic performance of the impeller. In conclusion, the optimization scheme has an ideal effect in increasing the efficiency and head of vortex pump.

The test of picturing the experiment flow field is carried out to make an analysis of the internal flow situation in the vortex pump, as shown in Figure 12. In the vortex pump, there exists a complex turbulent flow composing of the circulating flow and throughflow, which is consistent with the numerical simulation results of vortex pump mentioned above.

According to the flow orbit of the axial streamline calculated by the numerical calculation of vortex pump in Figure 12(a), the fluid flows uniformly and parallelly from the inlet of vortex pump and changes its orbit when flowing through the backward chamber of vortex pump, with lots of vortices forming at the junction of the backward chamber and the vaneless chamber, resulting in the energy loss. After analyzing the experimental measurement of the fluid orbit in Figure 12(b), it can be concluded that even though the movement of the fluid in the vortex pump is rather complex, the main type of the flow motion is the throughflow and circulating flow. What is more, there is a consistency in the conclusion drawn by the analysis and comparison between the numerical simulation decomposition and the experimental test resolution to the axial streamline. Once more, the test of the internal flow field in the vortex pump indicates that the numerical simulation referred to above has a great reliability.

The flow pattern of vortex pump mainly includes throughflow and circulating flow. There are secondary flow vortices with unknown size, quantity, and distribution position in the fluid flow of the vortex pump. The 


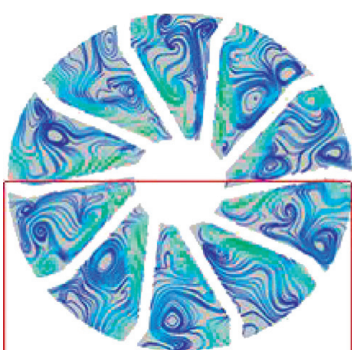

Original design model

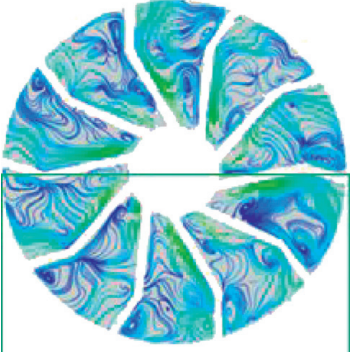

Optimization model

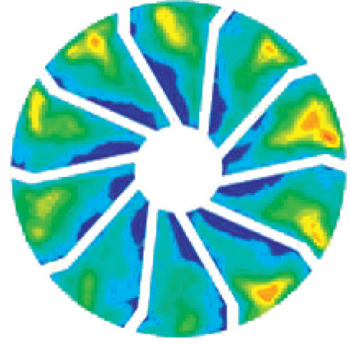

Original design model

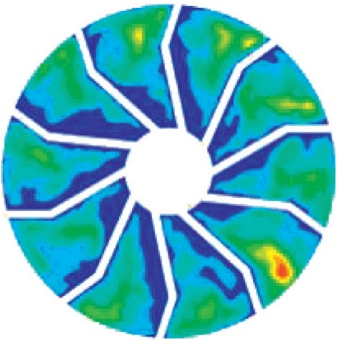

Optimization model

(a)

(b)

FIgURE 11: Comparison of internal flow field before and after optimization. (a) Velocity streamline. (b) Vorticity.

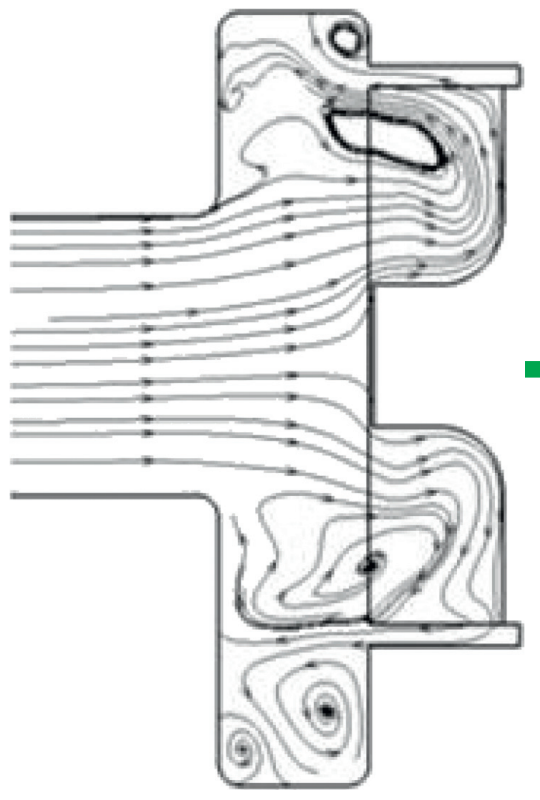

(a)

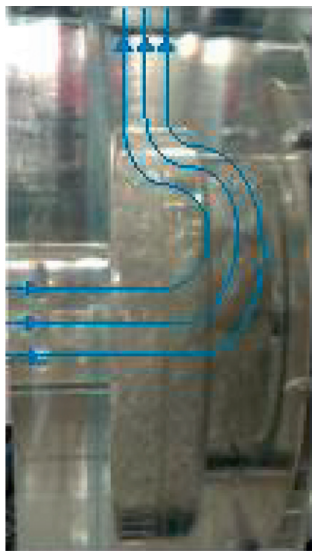

Decomposition of
flow patterns in vortex pumps

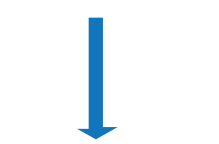

Circulating flow

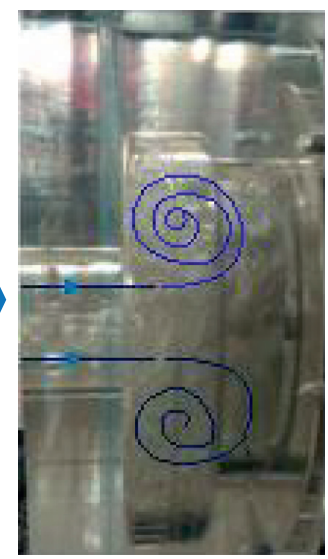

(b)

Figure 12: Streamline distribution of internal flow in vortex pump. (a) Simulation result. (b) Experimental results.

combination of these factors leads to the decline of the overall efficiency of the vortex pump. The throughflow flows through the inlet of vortex pump by the work of the impeller, and the existence of the circulating flow is the main reason affecting the vortex pump efficiency. Yet, just because of the circulating flow, it is possible to transport the solid-liquid two-phase flow especially with large particles at a relatively strong flow capacity. It is obvious that nondirectional vortices are easily generated in the region of no cavity, which leads to the disorder of flow structure. When the impeller of the vortex pump does work on the fluid through rotation in the back shrinking cavity, the flow in the whole vortex pump can be divided into the above two types. Now a new topic is put forward, which is how to increase the efficiency of vortex pump on the condition of not affecting the large particle flow capacity. And the key of solving this problem is the structure 
change of the throughflow and circulating flow, which is exactly the further research focus of our team.

\section{Conclusions}

Design optimization of the vortex pump impeller with folded blade has been performed through combined application of orthogonal test and computational fluid dynamic simulation. The external performance property and the internal flow structure of the pump model designed have been further measured experimentally. Main conclusions are given as follows:

(1) Orthogonal design optimization shows that the forward-deflecting blade impeller is superior to the backward-deflecting one. As key factors, following the order of importance, the deflection angle blade at the inlet $(\alpha)$, the position of blade deflecting point $(M)$, the chamfering radius $(r)$ at the blade deflecting point, and the wedge $(W)$ of deflecting blade, successively affects the flow rate at the maximum efficiency. The order of importance of those factors affecting the head at the maximum efficiency is demonstrated to be as follows: the wedge $(W)$ of deflecting blade, the position of blade deflecting point $(M)$, the deflection angle of the blade inlet $(\alpha)$, and the chamfering radius $(r)$ at the blade deflecting point. The order of important of those factors affecting the efficiency is as follows: the wedge $(W)$ of deflecting blade, the chamfering radius $(r)$ at the blade deflecting point, the position of blade deflecting point $(M)$, and the deflection angle blade at the inlet $(\alpha)$. But the order of important to the shaft power at the maximum efficiency changes to be as follows: the deflection angle blade at the inlet $(\alpha)$, the position of blade deflecting point $(M)$, the chamfering radius $(r)$ at the blade deflecting point, and the wedge $(W)$ of deflecting blade.

(2) Through the range analysis and comparative analysis, the optimum impeller type and blade combination of vortex pump are obtained in this orthogonal experimental design: the deflection angle of the blade inlet $(\alpha)$ with $30^{\circ}$ of forward-curved blade, $2 / 3 \mathrm{~L}$ of the blade of position of blade deflecting point $(M), 3 \mathrm{~mm}$ for the chamfering radius size $(r)$ of deflecting point, and the axial wedge for the wedge $(W)$ of deflecting blade.

(3) There exists an optimum combination among the deflection angle blade at the inlet $(\alpha)$, the position of blade deflecting point $(M)$, the chamfering radius size $(r)$, and the wedge $(W)$ of deflecting blade. It has a great meaning for improving the hydraulic performance of vortex pump. The configuration of multiple factors is supposed to be taken into account synthetically in the design of vortex pump in order to improve the whole performance of vortex pump.

\section{Abbreviations}

\begin{tabular}{|c|c|}
\hline$R_{1}-F_{2}:$ & Forward-deflecting blade \\
\hline$F_{1}-R_{2}$ & Backward-deflecting blade \\
\hline$D_{2}:$ & Impeller outer diameter $\mathrm{mm}$ \\
\hline$B:$ & Blade width $\mathrm{mm}$ \\
\hline$N:$ & Blade number \\
\hline$D_{3}:$ & Base diameter mm \\
\hline$L:$ & Leafless cavity width $\mathrm{mm}$ \\
\hline$e:$ & $\begin{array}{l}\text { Clearance between outer diameter of impeller } \\
\text { and shell } \mathrm{mm}\end{array}$ \\
\hline$\alpha:$ & Deflection angle of blade inlet \\
\hline$\beta:$ & Deflection angle of blade outlet \\
\hline M: & Deflecting point position of blade \\
\hline$r:$ & $\begin{array}{l}\text { Chamfer in the deflecting point position of blade } \\
(\mathrm{mm})\end{array}$ \\
\hline$W:$ & Wedge of deflecting blade \\
\hline$Q:$ & Inlet flow rate of pump $\left(\mathrm{m}^{3} / \mathrm{h}\right)$ \\
\hline$H:$ & The head of pump (m) \\
\hline$\eta:$ & Efficiency (\%) \\
\hline$P:$ & Shaft power $(\mathrm{kW})$ \\
\hline$K_{1,2,3}:$ & Data of four factors at the same level \\
\hline $\bar{K}_{1,2,3}:$ & Average data of four factors at the same level \\
\hline & Range of data \\
\hline$A_{1}, A_{2}, A_{3}:$ & Deflection angle of blade inlet: $30^{\circ}, 45^{\circ}$, and $60^{\circ}$ \\
\hline$B_{1}, B_{2}, B_{3}:$ & $\begin{array}{l}\text { Deflecting point position of blade: } 2 / 3 \mathrm{~L}, 3 / 4 \mathrm{~L} \text {, } \\
\text { and } 4 / 5 \mathrm{~L}\end{array}$ \\
\hline$C_{1}, C_{2}, C_{3}:$ & $\begin{array}{l}\text { Chamfer in the deflecting point position of } \\
\text { blade: } 3 \mathrm{~mm}, 4 \mathrm{~mm} \text {, and } 5 \mathrm{~mm}\end{array}$ \\
\hline $\begin{array}{l}W_{1}, W_{2} \\
W_{3}:\end{array}$ & $\begin{array}{l}\text { Wedge of blade: axial wedge, radial wedge, and } \\
\text { antiaxial wedge. }\end{array}$ \\
\hline
\end{tabular}

\section{Data Availability}

The data used to support the findings of this study are included within the article.

\section{Conflicts of Interest}

The authors declare that there are no conflicts of interest regarding the publication of this paper.

\section{Acknowledgments}

This work was partially supported by the National Natural Science Foundation of China (51969014 and 51609113), the China Postdoctoral Science Foundation (2018M633651XB), the Outstanding Young Talents (20JR10RA204), and the Natural Science Foundation of Gansu (20JR5RA456), with the Hongliu Outstanding Young Talents Funding Scheme of Lanzhou University of Technology. 


\section{References}

[1] H. Quan, B. Fu, R. Li et al., "Research stage and development tendency of vortex pump," Fluid Machinery, vol. 44, no. 9, pp. 36-40, 2016.

[2] Y. Wang, W. Shi, Y. Dong et al., "Present status and development prospect of vortex pump," Drainage and Irrigation Machinery, vol. 22, no. 2, pp. 8-11, 2004.

[3] K. Rutschi, "Die arbeitsweise von freistrompumpen," Schweizerishe Bauzeitung, vol. 8, pp. 86-32, 1968.

[4] G. P. Schivley, "An analytical and experimental study of a vortex pump," Transactions of the ASME, vol. 12, pp. 88-90, 1970.

[5] O. Hideki et al., "The reasearch internal flow of and performance of a vortex pump (The front page)," in Preoceedings of the Japan institute of machinery, Jakarta, Indonesia, July 1982.

[6] M.. Aoki, "The research status of vortex pump," Turbomachinery, vol. 12, no. 2, 1984.

[7] Z. Cai, "Eddy current pump," Pump Technology, vol. 2, no. 1, pp. 30-35, 1979.

[8] M. Zheng and Q. Cheng, "The inner flow of vortex pump and raising its efficiency," Journal of Fluid Engineering, vol. 169, pp. 143-149, 1991.

[9] W. Shi, Y. Wang, Y. Sha et al., "The Study internal flow of a vortex pump," Transactions of the Chinese Society of Agricultural Machinery, vol. 37, no. 1, pp. 68-70, 2006.

[10] Y. Sha, "Effect of impeller location and flow measurement in volute of a vortex pump," Transactions of the Chinese Society for Agricultural, vol. 41, no. 11, pp. 57-62, 2010.

[11] H. Quan, B. Fu, R. Li, G. Li, Z. Zhang, and J. Li, "Mathematical model of energy conversion mechanism in screw centrifugal pump based on load criteria of blade airfoil," Engineering Computations, vol. 34, no. 7, pp. 2168-2188, 2017.

[12] R. Zhu, B. Su, X. Wang et al., "Numerical simulation and experiment of influence of hem on performance of vortex pump," Journal of Drainage and Irrigation Machinery Engineering, vol. 28, no. 5, pp. 398-401, 2010.

[13] W. Shi, X. Sun, W. Lu et al., "Orthogonal experiment on performance of submersible mining pump," Journal of Drainage and Irrigation Machinery Engineering, vol. 29, no. 1, pp. 6-10, 2011.

[14] H. Wang, W. Shi, W. Lu et al., "Optimization design of deep well pump based on Latin square test," Transactions of the Chinese Society of Agricultural Machinery, vol. 41, no. 5, pp. 56-63, 2010.

[15] X.-q. Cong, S.-q. Yuan, and D.-q. Yuan, "Research of the orthogonal tests of a sewage water pump having no overloads," Transactions of Chinese Society of Agricultural Machinery, vol. 36, no. 10, pp. 66-69, 2005.

[16] Y. Shen, S. Yuan, W. Lu et al., "Orthogonal test design method based on numerical simulation for non-overload centrifugal pump with complex impeller," Transactions of the Chinese Society for Agricultural Machinery, vol. 41, no. 9, pp. 22-26, 2010.

[17] C. Wang, H. Peng, J. Ding et al., Probability Statistics Group of Mathematical Mechanics System: Orthogonal Design Method, Petrochemical Industry Press, Beijing, China, 1976.

[18] J. Wang, "The experimental study on the hydraulic performance of vortex pump," Drainage and Irrigation Machinery, vol. 7, no. 3, pp. 8-15, 1987.

[19] X. Guan, Handbook of Modern Pump Technology, pp. 234238, Aerospace Press, Beijing, China, 1995.
[20] H. Quan, J. Cheng, Y. Guo, L. Kang, and G. Peng, "Influence of screw centrifugal inducer on internal flow structure of vortex pump," ASME Journal of Fluids Engineering, vol. 142, no. 9, 2020.

[21] H. Quan, Y. Chai, R. Li, and J. Guo, "Numerical simulation and experiment for study on internal flow pattern of vortex pump," Engineering Computations, vol. 36, no. 5, pp. 1579-1596, 2019.

[22] H. Quan, Y. Chai, R. Li, G.-Y. Peng, and Y. Guo, "Influence of circulating-flow's geometric characters on energy transition of a vortex pump," Engineering Computations, vol. 36, no. 9, pp. 3122-3137, 2019.

[23] H. Quan, Y. Guo, R. Li, G. Peng, Q. Su, and Y. Chai, "Optimization design and experimental study of vortex pump based on orthogonal test," Science Progress, vol. 103, no. 1, pp. 1-20, 2019.

[24] J. L. Parrondo-Gayo, J. Gonza'lez-Pe'rez, and J. n. Ferna 'ndez-Francos, "The effect of the operating point on the pressure fluctuations at the blade passage frequency in the volute of a centrifugal pump," Journal of Fluids Engineering, vol. 124, no. 3, pp. 784-790, 2002.

[25] L. He, F. Wang, M. Yang et al., "Modal analysis of doublesuction centrifugal pump impellers," in Proceeding of 2010 International Conference on Pumps and Fans, Hangzhou, China, October 2010.

[26] M. liu and D. G. Gorman, "Formulation of Rayleigh damping and its extensions," Computers \& Structures, vol. 57, no. 2, pp. 277-285, 1995.

[27] M. Zheng, Y. Shouqi, and C. Chen, "Influence of structural parameter of a vortex pump on its performance," Transactions of the Chinese Society for Agricultural Machinery, vol. 31, no. 2, pp. 46-49, 2000.

[28] S. Yi, J. Wang, M. Yang et al., "The internal flow and the suction property of vortex pump based on experimental study," Pump Technology, vol. 4, pp. 9-12, 2003.

[29] Y. Wang, X. Huo, and F. Lusquiños, "Multiobjective optimization design and performance prediction of centrifugal pump based on orthogonal test," Advances in Materials Science and Engineering, vol. 2018, Article ID 6218178, 2018.

[30] Y. Xu, L. Tan, S. Cao, and W. Qu, "Multiparameter and multiobjective optimization design of centrifugal pump based on orthogonal method," Proceedings of the Institution of Mechanical Engineers, Part C: Journal of Mechanical Engineering Science, vol. 231, no. 14, 2017.

[31] C. X. Ye, M. Umezu, A. H. Nugent, and V. P. Chang, "The spiral vortex pump-design concept, flow characteristics \& test results," Journal of Artificial Organs, vol. 14, no. Suppl.1, pp. 46-49, 1990.

[32] M. Umezu, C. X. Ye, A. H. Nugent, and V. P. Chang, "Advantage of the spiral vortex design in pneumatic blood pumps as demonstrated by dye-washout tests," Journal of Artificial Organs, vol. 14, no. Suppl.4, pp. 31-33, 1990.

[33] K. Imachi, I. Fujimasa, K. Mabuchi et al., "A newly designed jellyfish valve for an artificial heart blood pump," Transactions of the American Society for Artificial Internal Organs, vol. 34, pp. 726-728, 1988.

[34] K. Iwasaki, M. Umezu, K. Imachi, K. Iijima, and T. Fujimoto, "Design improvement of the Jellyfish valve for long-term use in artificial hearts," The International Journal of Artificial Organs, vol. 24, no. 7, pp. 463-469, 2001.

[35] P. Tan, Y. Sha, X. Bai et al., "A Performance test and internal flow field simulation of a vortex pump," Applied Sciences, vol. 7, no. 12, p. 1273, 2017. 